\title{
A RED QUEEN MODEL OF PERSONALITY
}

\author{
DOUGLAS ROY ${ }^{1 *}$ AND BRONWEN ROY ${ }^{2}$ \\ ${ }^{1}$ University of New South Wales, Australia \\ ${ }^{2}$ Hawksbury Institute for the Environment, Western Sydney University, Australia
}

\begin{abstract}
Genetics underpins many ways in which individuals differ. The purpose of this paper is to advance a model with testable hypotheses regarding the cause of the genetic basis of personality. We proceed by developing the suggestion that diversity in personality genes evolved to constrain parasitic elements of culture and discuss its implications. In particular, a critical test of this hypothesis is whether personality genes show fluctuating linkage disequilibrium and a dispersed distribution throughout the genome. It is further suggested that this Red Queen process has facilitated the evolution of intelligence and allowed a higher mutation rate in relevant genes. The model's empirical predictions are discussed in the context of alternative explanations, including those regarding intragenomic conflict, economics, and heterozygote advantage.
\end{abstract}

Keywords: Parasite, culture, meme, personality, intelligence, intragenomic conflict, comparative advantage, Flynn Effect

\section{AIMS AND OVERVIEW}

Competition eliminates competitors. Consequently, Natural Selection often leads to consistency in traits as genes for optimal design replace alternatives. Many characteristics of human psychology are indeed uniform and universal, and this is consistent with a role for selection in shaping their fundamental features (Pinker, 1997). But just as ubiquitous across population s are the ways in which individual differ, such as indicated by measures of personality traits (Eysenck, 1992). Why has this pattern of variety evolved? One possibility is that culture has stimulated evolutionary processes that preserve this genetic diversity (Roy, 2017a). Our aim is to further develop this notion into a testable model for how Natural Selection regulates the genetic basis of personality. After showing how its predictions can be tested, we extend the logic to consider implications for the evolution of intelligence.

\section{* Corresponding author: Douglas Roy; E-mail: droy8625@uni.sydney.edu.au}

This is an open-access article distributed under the terms of the Creative Commons AttributionNonCommercial 4.0 International License (https://creativecommons.org/licenses/by-nc/4.0/), which permits unrestricted use, distribution, and reproduction in any medium for non-commercial purposes, provided the original author and source are credited, a link to the CC License is provided, and changes - if any - are indicated. 


\section{PREMISES}

Since this paper is concerned with how personality, evolution, and culture interrelate, it is important to define each of these before turning to how they may interact.

\subsection{The biosocial nature of personality}

People differ psychologically in ways that are stable over time and some of these differences can be measured by psychometric means, such as behavioral tests and questionnaires. Correlations between these variables are conceived of as personality traits, such as 'sociability' and 'impulsivity.' Traits can be conceived as forming yet higher-order continuums, such as ExtraversionIntroversion, Stable-Emotional, and so forth. Such higher-order groupings are typically termed personality dimensions.

It is important for our purposes to emphasize the biosocial nature of these dimensions. On the one hand, there can be little doubt that genetic and biological factors are important determinants of personality. For example, heritability studies consistently find that genetic factors contribute to roughly half of the variation in psychometric measures of extraversion (the genetic component or $\mathrm{h}^{2}$ ranging from .4 to .6), neuroticism $\left(\mathrm{h}^{2}\right.$ ranging from .4 to .5$)$ and psychoticism ( $\mathrm{h}^{2}$ ranging from .3 to .6) (reviewed in Zuckerman, 1991; 2005) with similar heritability figures reported in twin studies for other traits that seem to be fairly similar, such as religious (Eaves et al., 1999) and political attitudes (Funk et al., 2012), as well as many other psychological factors (Chabris et al., 2015).

On the other hand, personality likely develops out of the interplay between each individual's unique genetic makeup and the various habits they absorb from culture (Eysenck, 1967; 1997; Zuckerman, 1991; 1994). To illustrate, Figure 1 shows a hypothetical depiction of these relations and the personality dimension, Psychoticism (Eysenck, 1993; Roy, 2017b). The relevant genes affect neurological pathways, such as those involving neurotransmitters like dopamine, which in turn influence psychological processes which interact with culture, such as the conditioning process of latent inhibition which shapes how individuals learn about various incentives. Genetic variation between individuals in these pathways lead to differences in the minds that emerge from interactions between these learning processes and the environment. In doing so, genetic variation may, for instance, moderate both how "creative" and "toughminded" a given individual tends to be, compared to other individuals, and hence these traits show statistical relations to form a higher-order dimension, in this case Psychoticism. 


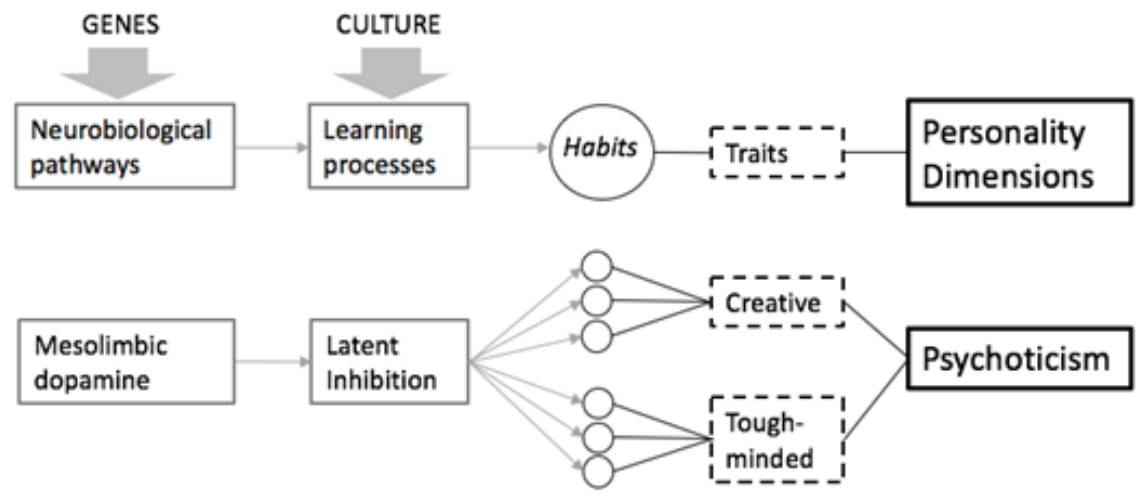

Figure 1. Biosocial relationship between genetic variance and personality. Ontogenetic pathways leading from genetic and cultural inheritance to the development of personality; and example showing genetic variance in Dopamine (DA) functioning resulting in the emergence of related habits forming trait creativity via its effects on learning processes governing attention.

The focus here is not on the details of how particular genes relate to particular traits. Many causal theories have been suggested as to how genetically varying individuals might develop different personalities even though they are exposed to the same cultural milieu (examples are reviewed in Zuckerman, 2005). The focus here is instead on why there is ultimately variation in these genes at all and why it might be maintained in the population rather than eliminated by Natural Selection.

\subsection{Natural selection}

We use the term gene here in the population geneticist's sense, that is, a gene can be any genetic material that acts as a replicator: a piece of information which makes copies of itself. Evolution consists of different varieties of replicators changing in their relative abundance, and evolution by Natural Selection refers to when a replicator's frequency changes specifically as a result of its own influence on the world (Dawkins, 1982) - assuming that the properties of the replicator which cause these influences do not decay too rapidly from copying errors (Williams, 1966).

Thus, a gene 'for' Extraversion refers here to any genetic replicator that, compared to genes with which it is competing, tends to affect an individual's level of Extraversion. To say that a gene is being selected for is to say that its frequency in a population is increasing over generations due to its phenotypic effects. 


\subsection{The red queen}

One type of selection process that can maintain genetic diversity in a population involves parasites (Hamilton, 1982). Parasite in the evolutionary sense means any evolving entity that is selected to benefit itself at the expense of its host. As parasites adapt, therefore, this often creates a selection pressure for counteradaptation in the host species, which then favors counter-counter adaptations by the parasites in turn, and so on, with each improvement made by one party favoring an offsetting counter from the other.

An important thing to note about parasites is that these arms races are not inherently symmetrical. Parasites have the evolutionary edge in that they can usually evolve more rapidly (due to parasites usually having shorter generation spans, faster mutation rates, more prolific reproduction rates, and other advantages). It is therefore difficult, if not impossible, for slower evolving host species to develop effective immunity for long before they are overrun by strains of parasites that swiftly adjust to exploit its weaknesses. And the more common any particular immune response becomes in a host population - that is, the more successful a particular adaptation is for coping with parasites - the more likely parasites will soon evolve to specialize in exploiting that particular source of immunity ${ }^{1}$.

The Red Queen theory holds that sexual recombination allows a process by which hosts can hold their own against rapidly evolving parasites (Hamilton, 1980; Jaenike, 1978; Morran et al., 2011). Sex can have this effect when the host gene pool contains many alleles conferring varying susceptibilities and levels of resistance to different parasite strains. The key reason is that parasites are selected to specialize to whatever type of host they commonly encounter. Since sexual reproduction makes individuals unique, this means that no parasites will encounter more than one host whose defenses are exactly the same. If there are many subtle genetic effects determining resistance to parasites, and if these differences are at many parts of the genome, then the shuffling of sexual reproduction means that no two hosts that a parasite encounters will be identical. The upshot is that often the parasite moving into a new host will suffer a loss in virulence when confronted with an array of immune defenses unlike those of the host it has most recently evolved to evade or subvert.

For example, suppose a gene-combination becomes common in the host population. Parasites will soon evolve to specialize in exploiting the defenses of this particular type of genotype. Meanwhile, dissimilar host genotypes will have an advantage, simply because they are scarcer and unlike what the parasites can currently infect most effectively. The rare genotypes will thus become more common, as the originally common genotype is driven towards extinction by the 
parasites. But as the new genotype becomes more common, the parasites will now be selected to exploit it instead, as it is now the common genotype and the type the parasites have specialized in has become less common. As the transiently abundant host genotype becomes the new target of parasites, this relaxes the extent to which other host-genotypes are suppressed. And as hostgenotypes become rare again, they eventually become favored by virtue of that rarity, and so on.

The general intuition of what such parasite coevolution means for host genes can be further illustrated by a metaphorical device borrowed from Hamilton (2001, p. 643). For simplicity, suppose there are three loci at which host genes vary. All possible combinations of such genes can be conceived of as represented on a three-dimensional space within a cube. The cube is imagined to be floating in water, with whichever part of the cube is highest representing the fittest and (therefore most common) genotype at any given time. Figure 2 depicts the parasites as clusters of grey dots, which are selected to exploit the most common host genotype, which corresponds to the highest portion of the cube at any given moment. The deleterious effect of parasites on their hosts is supposed

(a)

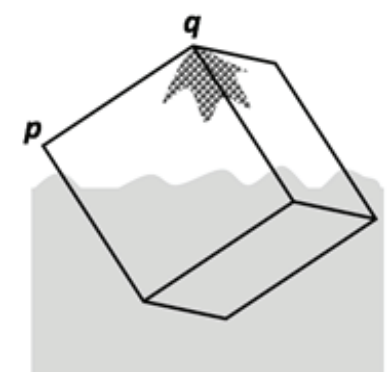

(b)

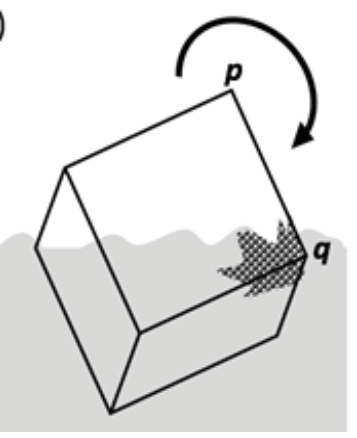

(c)

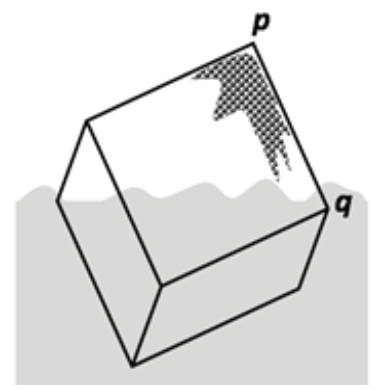

Figure 2. Hamilton's Hypercube. (a) The fittest genotype is at point $q$, which the parasites evolve to exploit. But by occupying point $q$, the parasites make it heavier, tipping it towards the water (b). In doing so they raise some other point, $p$, to the highest fitness. (c) The parasites now evolve towards $p$, which will cause that point to also tip, thus continuing the process (modified from cover image of Hamilton, 2001).

to act like weight on the genotypes they infect. Therefore, as parasites evolve to occupy the region of the fittest combination of host genes, this is imagined as them crowding towards that position on the cube. The effect is to tip the cube so that another point becomes the fittest instead, to which the parasites soon rush. 
Although impressionistic, this thought experiment mimics how constantly evolving parasites continuously change whichever particular set of host genes is optimal. In formal models based on biologically reasonable assumptions, the most probable behavior for parasite-host systems is this constant cycling, with genetic variance being preserved in the host-population (Hamilton, 1980; Hamilton \& Zuk, 1982). Theoretical modeling (Ebert \& Hamilton, 1996), phylogenetic contrasts (Hamilton \& Zuk, 1982), field studies (Auld, Wilson, \& Little, 2014) and manipulative experiments (Sackton et al., 2007) indicate the Red Queen indeed operates this way in nature, and may be an explanation for the evolution of sexual reproduction itself (for reviews, see Hamilton, 2001; Ridley, 1993, and for broader reviews of host-parasite evolutionary processes see Schmidt-Hempel, 2008; 2011). An interesting feature captured by this cube model is that the most dramatic cycling will be between two opposite corners of the cube at any one time (the highest and the lowest), while most of the other corners move relatively less. The constant tipping caused by the parasites, and waves in the water (representing sources of environmental noise, such as other parasites, seasonal fluctuations, and so forth) can messily jostle the cube around, changing which two corners are most intensely involved with the parasites from time to time. More formal modeling indicates this sort of behavior is likely when there are many types of parasites, with many varieties of genes cycling at varying and subtle amplitudes (Rabajante et al., 2016).

The validity of the hypothesis that Red Queen processes are the cause for why sex evolved is not of concern here. What is relevant is that, once evolved, the process can function to reduce the average virulence of parasite populations through maintaining variance in host genes (Hamilton, 1996).

\subsection{Parasitic culture}

Natural Selection is a substrate neutral process (Dennett, 1995). That is, it depends on the differential survival of replicators, regardless of whether those replicators are made of DNA or encoded in some other medium. Many aspects of culture are transmitted in a sufficiently similar fashion to the population geneticist's definition of a gene to be considered replicators (Dawkins, 1976). Although controversial, this extension of Darwinism to examining culture has been defended at length elsewhere (e.g. Blackmore, 2010; Dennett, 2006; 2017; Tyler, 2011). It is sufficient to note here that no argument appears to have been made that clearly disqualifies the concept or seriously undermines any aspect of it relevant to the present model (Roy, 2017a). Cultural replicators are sometimes termed memes, and defined as the smallest cultural elements (ideas, thoughts, 
behavior patterns) that can produce copies with enough reliability such that it can follow that a variety is becoming more or less common (Dennett, 1995).

The term parasitic meme shall be used here to refer to any such parasitic cultural replicators that have a negative effect on human genes (Ball, 1984). In the extreme, there are ideas that lead some people to have no surviving offspring, as with celibate nuns or suicide bombers. Less extreme might be innumerable other callings that tempt people to have fewer offspring, make less parental investment in the offspring they have, devote less resources to finding and seducing an optimal breeding partner, risk more in the pursuit of goals which have no positive fitness payoff, and so on. The key point here is that, like biological parasites, culture can evolve in ways that generate costs to the genes of their human hosts, making those genes less likely to be represented in future generations (Sahneh \& Scoglio, 2013).

Numerous considerations suggest that much of culture is likely to consist of parasitic tendencies. A fundamental reason relates to how memes get passed to future generations: culture is more often transmitted among unrelated individuals than it is between parents and offspring (Richerson \& Boyd, 2006), as habits and ideas can spread between any two individuals connected by a common "cultural universe" (Sowell, 2015). There is an important evolutionary difference between replicators which reproduce by being passed from one unrelated individual to another and other replicators which get passed down from parent to offspring (Hamilton, Axelrod, \& Tanese, 1990). The former is expected to evolve to manipulate behavior in ways detrimental to the latter (Dawkins, 1990). Given that much, if not most, memes replicate from individual to individual, rather than strictly following the genes of their hosts' descendants, it may be predicted that selection will favor many changes in cultural replicators despite reducing the fitness of hosts who imbibe and transmit them.

Another significant factor concerns the remarkable capacities of humans to design parasitic culture. Humans have come up with all sorts of ingenious tricks to manipulate the behavior of others into thinking things that affect the Darwinian fitness of human genes (Trivers, 2000). Indeed, there might have even been selection for human genes to manipulate the thoughts of the person to act in ways counter to other genes within the same genome (Haig, 2001, pp. 161-177). What is crucial to note here then is that culture is cumulative: even if a meme designed by some individual benefits the fitness of their genes at the expense of someone else's, the same meme might go on and continue to replicate in other minds long after the original parties have passed from the scene (Barkow, 1989; Hamilton, 2001).

In sum, there are reasons for supposing that a portion of culture will propagate at the expense of the human genes, and that deleterious ideas have a 
capacity to pool over time (for further reasons, see Roy, 2017a). If these memes have had non-negligible effects on human fitness, it is likely that these aspects of culture have impacted the human genome in similar ways to biological parasites.

\section{THE MODEL}

So far, we have outlined how (1) genetic variation in psychobiological pathways acts as a prism through which cultural effects are filtered and modified; (2) personality emerges from these interactions; (3) a significant portion of culture can be regarded as consisting of parasitic replicators; and (4) evolving parasites generate a selection pressure which maintains diversity in genes affecting immunity.

From these premises, it follows that Red Queen dynamics could explain personality since it seems that personality genes create diversity in the psychological pathways with which parasitic culture must contend. Theories of personality ontogeny already suggest many such candidate variables influence how memetic parasites infect minds, and some examples are touched on below. It is a small step to propose that personality genes are preserved in the population because of parasitic memes. Sex means that personality genes will be combined and re-combined incessantly into unprecedented amalgamations in each generation so that parasites will never encounter exactly the same mind twice. Since each person's psyche represents a new and subtly different selective environment to which the memes will have to adapt, the evolution of the virulence of memetic parasites will be constrained.

In short, the basic Red Queen dynamics may apply with identical logic to both biological and cultural parasites, although affecting different classes of genes in each case; immunological pathways in the former and psychological in the latter. There is nothing specific in all the Red Queen models that prohibit this extension given the premises we have outlined above. It follows that conclusions from the Red Queen literature can be applied in order to derive novel and testable predictions concerning psychological phenomena.

\section{EXAMPLES}

Some examples are given here of how genes for personality traits might mediate parasitic virulence. We focus here on Arousal-Regulation and ReinforcerSensitivity theories of personality. These approaches have elsewhere already been extended to interact with a range of cultural phenomena (e.g. Eysenck, 1977). Here they are re-interpreted in serving "immunological" functions in 
order to illustrate some ways in which the present theory might relate to existing personality psychology ${ }^{2}$.

\subsection{Arousal-Sensitive mutants}

Two of the most influential psychobiological theories of personality are the arousal-regulation theories of Extraversion-Introversion (Eysenck, 1967; 1997) and the conceptually similar account of Sensation Seeking (Zuckerman 1994; Zuckerman \& Glicksohn, 2016). These views hold that personality is partly determined by differences in how "arousable" individuals tend to be and the effects of stimulation intensity on performance, as depicted in Figure 3a. At low levels of arousal, it is difficult to perform most psychological tasks, such as learning, but with higher levels, performance tends to improve, until at some point further increases in arousal bring only diminishing and eventually negative returns. Thus, a person will acquire and perform associations, skills, habits, etc. at some optimal intensity of stimulation. Too high and too low levels of stimulation are unpleasant and so individuals tend to behaviorally regulate their stimulation, such as by choosing more intensely stimulating environments when they are under-aroused and withdrawing to quieter places when overaroused. But that optimal level of stimulation is not the same between individuals because people differ in their arousability. People who are less easily aroused tend to develop extraverted patterns of behavior and habitually seek out stronger levels of stimulation, as compared with more easily aroused individuals, who develop introverted patterns of behavior.

Since a meme is an information pattern that must be both learned and behaviorally expressed, the effectiveness (i.e. "learnability" and efficiency of expression) of varieties of memes in infecting their hosts and spreading also has an inverted U-shaped relationship with arousal. Therefore, the arousability construct may be an important part of the environment to which memes must evolve if they are to successfully replicate.

When encountering the mind of an introvert, for example, varieties of memes that thrive in less intensely stimulating environments would tend to have an advantage, while memes better adapted to the sort of nervous system that characterizes extraverts would be at a disadvantage. Conversely, ideas better suited to exploiting an introvert's mentality may not be sufficiently exciting to become well-learned, or even noticed, by someone very high on extraversion. To take an extreme case, the same con, for instance, pitched in the same way, will be unlikely to fool everyone in a room equally well if some people are too drowsy (or too excited) to pay attention. If each individual has a different 
optimal level of arousal, then each host a meme encounters represents a subtly different environment to which a meme must adapt.

(a)

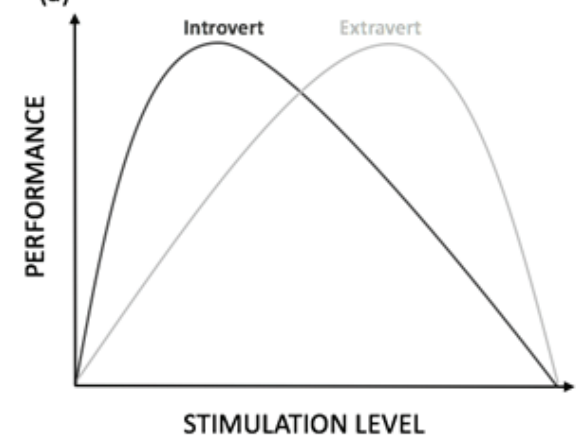

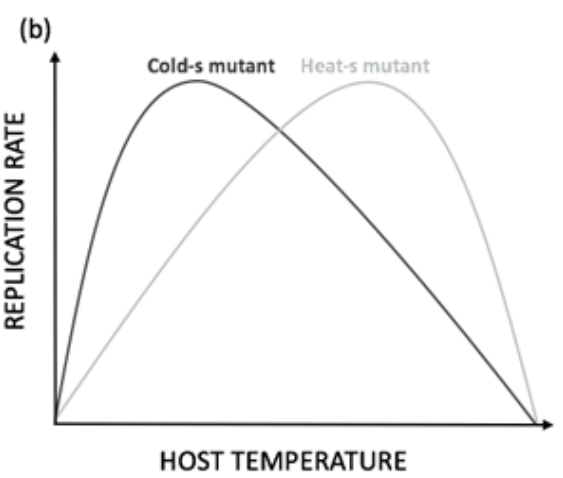

Figure 3. Differently sensitive mutants. Two curves represent the differences in the relationship for individuals low and high on Extraversion (a) (modified from figure 37 in Eysenck, 1967): an individual's position on the curve corresponding to his or her current arousal state, and level of performance at that level of stimulation. Similarly, two curves depict maximal levels of reproduction by two different strains of viruses evolved to specialize at particular temperature ranges (b).

How variation in the "arousal" construct is relevant can be made clearer by considering parallels with biological parasites. Biological parasites also evolve to specialize and operate at narrow, optimal levels of host-related parameters. For example, as illustrated in Figure 3b, viruses adapt to maximally exploit only limited temperature ranges (giving rise to so-called "temperature-sensitive mutant" strains). It is experimentally well-established that when a virus evolves to occupy a cooler optimal temperature this can result in marked reductions in virulence when descendants of that pathogen are returned to the warmer conditions (White \& Fenner, 1994, pp. 220-221). In fact, this technique has played important roles in the development of live-virus attenuated vaccines. Similarly, as a meme evolves to be optimal (high virulence) in a highly extraverted environment it will likely be evolving in a direction away from what is optimal in a more introverted environment (and vice versa).

In short, the analogue with the relationship between viral parasites and specific temperature ranges suggests how sexual recombination could produce the sort of disruptive selection necessary to attenuate memetic virulence by shuffling a large number of alleles, with each individually having a small effect on arousability. It may be added to this point that the concept of general arousal is of course a simplification: there may be a number of arousal processes 
associated with different neurotransmitters or functional circuitries in the nervous system, and these may vary between individuals in ways related to personality (Trofimova \& Robbins, 2016). There are therefore a number of ways in which genetic variation could contribute to disruptive variations in the selective environment in which memes must adapt.

If the above reasoning is valid, diversity in personality within a group situation should affect how easily participants are fooled. In particular, an experimental prediction of the Red Queen model is that a parasite that has been selected in a genetically homogenous population should be less infectious when introduced to groups characterized by a different genetic makeup (Ebert \& Hamilton, 1996). The plausibility of the Red Queen account as an explanation for personality could be tested experimentally by taking infectious memes and developing them to become progressively more successful at tricking subjects when collected in groups of alike personalities (e.g. a group of Extraverts). On this view, the resulting memes should be significantly less virulent - less able to 'trick'- people when introduced to groups either at opposite personality extremes (e.g. groups of Introverts) or of a more heterogeneous composition.

\subsection{Anxiety and inflammation}

One of the main features of reinforcer-sensitivity theory is the Behavioral Inhibition System or BIS (Corr \& McNaughton, 2012; McNaughton \& Corr, 2004). Individuals higher on measures of BIS also tend to be more sensitive to punishment, more loss averse, and tend to differ in trait anxiety (Corr \& McNaughton, 2012). Thus, it is easy to see how subtle and genetically determined inter-individual differences in the reactivity of BIS are likely to substantially affect the cultural transmission in a population.

For example, the fundamental role of the BIS is to detect and resolve goalconflict. Whenever two or more goals are active at the same time, this is detected by the hippocampus, which responds by producing an output that increases the valence of negative associations related to those goals. This activity continues recursively and the negative valence of concurrently active goals is progressively amplified until only one goal remains to direct behavior. Although descriptively simple, this process can have complex influences on emotional processes, memory, and behavior (Gray \& McNaughton, 2000; McNaughton \& Wickens, 2004).

It is also interesting to note that Gray and McNaughton (2000) suggest the activity of the BIS is analogous to the general inflammation response: negative valence is escalated until the replicators that have produced the least harmful consequences in the past prevail in competition while the most detrimental are 
made less likely to come to mind in the future. For instance, particular behavioral patterns that have been corrected in the past by feedback can be specifically inhibited as a result of similar experiences and their effects opposed by other behavior patterns released by the BIS. Conversely, the sorts of behavior patterns that are likely to be released by the septo-hippocampal system's output are precisely behaviors that have minimized fitness-reducing consequences in the past, such as passive avoidance (McNaughton \& Corr, 2004). This effect seems functionally similar to the specific immune responses of mammals and birds, which responds when antigens that are detected by intensifying the production of whichever particular antibodies had been successful in fighting similar pathogens in the past.

\subsection{Behavioral activation and impulsivity}

Like the BIS, the Behavioral Activation System (BAS) plays a major role in the reinforcer-sensitivity theory of personality. The BAS is instantiated largely through thalamocorticostriatal circuitry (Corr \& McNaughton, 2012). In addition to governing individual differences in trait impulsivity, sensitivity to reward, and the acquisition of habits (Corr, 2004), these same pathways have been implicated in major aspects of many cognitive processes involving goaldirected decision making (for reviews, see Balleine, Delgado, \& Hikosaka, 2007; Balleine \& O'Doherty, 2010; Bradfield \& Balleine, 2017). There are many ways that individual differences in BAS are therefore also likely to influence how different individuals deal with cultural parasites.

For example, there is growing evidence that animals respond to biological parasites through behaviors sensitive to incentives (Wong et al., 2015). For instance, organisms may moderate the virulence of pathogens by adjusting the particular types and quantities of food they seek out, such as seeking out plants with medicinal properties (Raubenheimer \& Simpson, 2009) or ingesting extra nutrients to compensate for costly immune reactions (Povey et al., 2014). Similarly, the cost of behavior $A$ can often be offset by adopting behavior $B$ : some species of parrot forage on poisonous plants to acquire nutrients, but offset the toxic effects by also ingesting particular types of clay (Burger \& Gochfeld, 2003). Similarly, behaviors people choose are also costly, whether these costs are in such obvious forms as toxic side effects of consuming certain reinforcements or simply opportunity costs from foregoing alternative sources of reward. Since such types of decision-making and sensitivity to the changing value of incentives is thought to depend on corticostriatal circuitry (Balleine \& O'Doherty, 2010), variation in the BAS between individuals may also represent 
differences in how well people can manage fitness-reducing impacts of particular cultural patterns.

A second way the BAS may influence patterns of enculturation is by influencing how consequences of cultural activities are perceived over time. The BAS seems to have a complex relationship with how individuals perceive and plan for the future (Corr \& Muinelli, 2017; Stoeber \& Corr, 2017). In particular, many of the neural structures that comprise the BAS are linked to impulsivity and so are involved in tasks where individuals must choose between outcomes that occur at different points in time (Frost \& McNaughton, 2017). The more steeply a delayed outcome is discounted, the more relatively immediate rewards tend to impact decision making relative to those in the future. Put differently, different people vary in their "time horizons": the lengths of time over which prospective costs and benefits of their behaviors affect their decision-making process (Sowell, 1980). Accordingly, steeper rates of delaydiscounting tend to be found in people with such pathologies characterized by short time horizons like ADHD (Barkley et al., 2001), addiction (De Wit, 2009) and violent crime (Lee et al., 2017).

At this point it is worth noting that genes can evolve to have negative impacts on the wellbeing of the bodies they influence so long as these effects occur mainly after they have replicated into future generations (Williams, 1957). Similarly, a meme is more likely to spread if its pleasurable effects are experienced relatively early and within periods of time that affect the person's decision making, while the painful effects are predominantly experienced after later (Sowell, 1980). Behaviors conditioned in this way can powerfully direct an individual's behavior even if they consistently produce much suffering as a result $^{3}$. Thus, cultural parasites should evolve so that their rewarding aspects are immediate and obvious, while their costs are concentrated beyond the point in time where they can affect decision-making and when the cultural trait has already been copied by others (Roy, 2017a). Hence a cultural activity, such as smoking, might cause some individuals severe costs that come too late to dissuade similarly minded individuals from adopting smoking by counterbalancing immediate benefits. However, variation in genes underpinning the BAS means that there is no particular time horizon in the host population for memes to exploit, and that there will also be individuals for which such costs loom larger in their decision-making than others.

The point here is not that the danger of cultural parasites implies people are better off if they are more far sighted: whether choosing particular patterns of behavior leads to net increases in Darwinian fitness is an empirical matter that likely varies from case to case. The point is that genetic variation ensures that each individual varies in their time horizon, and so this can act as a factor counteracting the evolution of memetic virulence. 


\section{EVIDENCE AND IMPLICATIONS}

\subsection{Patterns of heritability}

As reasoned above, stable psychological phenotypes (e.g. personality traits) result from the interactions between genetic and memetic replicators. Such traits can thus be viewed as the psychological analogue of biological phenotypes resulting from the interaction between the genes of hosts and parasites. In other words, personality traits are equivalent to the biological measures of parasiteload in immunological studies. Patterns of heritability should therefore be similar to both personality traits and indices for infection such as biological parasite-load.

Specifically, evidence of a high contribution to the personality of offspring by parents, beyond their genetic contribution, would count against the present thesis. This is because the Red Queen is supposed to maintain a high heritability of fitness that functions to protect individuals from the virulence of their parents' parasites in particular (Hamilton, 2001). This point becomes obvious by noting that, by the time a parent reproduces, many of their parasites have been evolving for a long time to exploit their particular, unique immune system. If the immune system of a parent and his or her offspring are very similar, then the offspring are therefore going to be especially vulnerable to their parents' parasites. Further, if the species is characterized by longevity and a long period of contact between relatives, as is the case in humans, transmission of such parasites is especially likely. Put simply, in the absence of a Red Queen process, the parasites that a newborn is most vulnerable to would be that of their parents, and a Red Queen process acts to ensure each child has a unique combination of the relevant genes so as to significantly disrupt transmission of these parasites. More precisely stated, the level of resistance individuals show to their parents' memetic parasites should be similar to the resistance offspring show to their parent's biological parasites. In the terminology of heritability studies, it is the shared environment component of heritability that is critical for testing this prediction ${ }^{4}$ : both the shared environment component of personality and of variation in infectious parasite-load should be small.

Evidence suggests that the heritability estimates of chronic infectious disease appears to vary in a similar range to that of personality; for instance, greater concordance rates for infection between monozygotic than for dizygotic twins (Cooke \& Hill, 2001). Both infectious diseases (examples include Höhler et al., 2002; Rovers et al., 2002, Williams-Blangero et al., 2002; for a review, see Kimman, 2001) and personality traits (Zuckerman, 2005) show substantial genetic determination, with little attributable to shared environmental sources ${ }^{5}$. Thus, regardless of whether the parasite is a worm, virus, or bacterium, it 
appears to manifest roughly the same heritability breakdown as personality measures.

\subsection{Fluctuating linkage disequilibrium}

Although cycling in the frequencies of genes is predicted, overt cycling is not necessary. Rather, the most straightforward implication is that there will be fluctuating patterns of Linkage Disequilibrium (LD) observed for genes related to immunity in the host species (Hamilton, 1980).

The reasoning behind this prediction can be understood by first explaining how LD arises. When certain genes do well in combination, they tend to become inherited together over evolutionary time. For example, when two (or more) genes from different loci create particularly successful phenotypes, Natural Selection results in a disproportionate number of offspring in the next generation tending to inherit that combination. These genes will have a statistical bias for co-occurring with each other as Natural Selection progresses, while mutations that move them closer together in the genome will be favored (because this reduces the chances of them being separated by meiosis). This tendency is what is meant by LD and when molecular methods detect significant LD this is often taken as evidence for selection.

Because co-adapting parasites rapidly evolve to exploit currently successful gene combinations, they thereby release previously suppressed variants, and so those previously suppressed combinations can later experience a resurgence in fitness. But the absolute frequency of many of these genes may not noticeably change as a result of a type of combination being suddenly more or less successful - especially in species with low rates of reproduction (Hamilton, 2001, p. 66), like humans. However, since LD between genes results when selection acts to favor some particular combinations, a change in selective advantage for particular combinations will likely register as a change in patterns of LD.

Thus, LD between combinations of genes affecting vulnerability to coevolving parasites should change capriciously and significantly. LD between one combination should only last for a short while, as parasites will evolve to drive down its success, automatically generating selection pressure for other combinations. Coevolving parasites should ensure strong LD arises but does not persist and so the relevant genes should tend to be scattered throughout the genome.

Indeed, the more dispersed such genes are throughout genome the more effective the sexual recombination process is likely to be in attenuating virulence, because genes further apart from each other in the genome are more 
likely to give rise to unusual combinations in future generations (for further explanation, see Hamilton, 2001, pp. 61-62).

Although less testable, it also follows from the Red Queen account there should be significant levels of epistasis observed for psychological traits determining fitness-related outcomes (Peters \& Lively, 1999). Epistasis refers to the phenotypic variation that occurs as a result of interactions in particular combinations of genes and that is over and above what would be expected from adding up the average individual effects of the genes involved. It is worth noting in this regard that significant evidence of epistasis in personality traits has already been reported (Penke \& Jakola, 2016).

Particular genes implicated in personality are only starting to be identified, though there is already direct evidence that selection has acted on alleles related to personality. For instance, high Psychoticism is implicated with schizophrenia and schizophrene-thinking (Eysenck, 1993; 1995), and several identified alleles associated with schizophrenia have been subject to strong positive selection in recent history (Crespi, Summers, \& Dorus, 2011). There is also evidence from a study of island populations that genes affecting Extraversion have been subject to rapid and recent selection resulting in population differences in average levels of these traits (Ciani et al., 2006). There is also evidence of changing relationships between fertility and personality reported in a study of women in the United States (Jakola, 2012). More generally, there is accumulating evidence that there has been much selection acting on human genes in even recent times (Voight et al., 2006; Williamson et al., 2007) and that much of this appears to involve genes expressed in the brain (Voight et al., 2006; Wang et al., 2005). Although fluctuating LD has not been tested for, strong and consistent relationships between personality traits and reproductive success would speak against a Red Queen model. However, where significant correlations between personality and reproductive success are found in samples no particular results appear to be consistent across studies (Penke \& Jakola, 2016).

Further investigations are needed to determine if genes affecting personality are subject to a Red Queen process. A Red Queen model for personality would be disproved if personality genes were (1) to be found in only concentrated regions of the genome, (2) if such genes were associated with only weak or no LD, or (3) if LD was in a consistent direction over many generations (Roy, 2017a). Since it is supposed that a Red Queen process confers advantages to genes as they become rare, it is also predicted that many personality genes should be ancient as they would tend to have been preserved for as long as parasitic culture has existed. These predictions can be tested in direct contrast to those derivable from alternative explanations of personality, with examples discussed below. 


\subsection{Intragenomic conflict}

Predictions following from our Red Queen explanation of personality can be contrasted with those derivable from intragenomic conflict theory (Haig, 2001). Intragenomic conflict involves a number of classes of genes: paternallyimprinted genes, maternally-imprinted genes, the genes for carrying out the imprinting process, and the genes for reading the imprinting. Imprinting here refers to a mechanism by which patterns of gene expression are determined by whether certain genes in an individual were inherited from its mother or father. That some genes can be imprinted in this way allows these different classes of genes to significantly bias phenotypes towards their own evolutionary ends. Each of these types has subtly but crucially different interests and so can evolve in antagonistic arms races with each other.

For example, consider a species where females mate with many different males. In this case, a maternally imprinted gene may 'want' to bias the behavior of the body it is in so as to be more altruistic towards its mother and her other offspring (because these particular individuals are likely to share copies of this gene and so helping them flourish will tend to also help this gene replicate). But a paternally imprinted gene is unlikely to exist as copies in any maternal siblings, since the mother will have had multiple mates - evolutionary 'rivals' of the father. Therefore, the paternally imprinted gene will be selected to bias its bearer towards selfish behavior, indifferent to or at the expense of the mother and her other children.

The specifics of the conflict theory do not concern us here (for a detailed account see Haig, 2001), but it may be noted that, in accordance with intragenomic conflict, imprinted genes show marked differential expression in the mammalian brain (Gregg et al., 2011), and influence over systems that are particularly likely to influence social behavior, such as testosterone and oxytocin signaling pathways (Mokkonen \& Crespi, 2015). The diversity in these genes and their interactions may powerfully affect social behavior (Brown, 2001), and so hint at a promising alternative evolutionary explanation of individual psychological differences.

Imprinted genes are both predicted by theory, and shown by some evidence, to be tightly-linked and show clustering in the genome (Haig, 1997; 2004). Moreover, if the process is being driven by an intragenomic arms race, we might further expect the emergence of the relevant genes to be correlated with each other; a mutation that gains the edge in, say, maternally-imprinted lines would provoke a corresponding evolutionary response in paternallyimprinted lines, and so on. Therefore, predictions regarding personality genes and intragenomic conflict lead to directly opposite predictions to those based on a Red Queen account: if personality is driven by intragenomic conflict arms 
races, personality genes will be clustered both in the genome and in their appearance in evolutionary time. But if personality is driven by Red Queen coevolutionary seething, personality genes should be scattered, and variants should be preserved over long periods once they arise.

\subsection{Comparative advantage}

The advent of exchange may have led to another selection pressure for maintaining diversity in personality genes and so provides an alternative to the Red Queen model. Exchange here refers to the voluntary trading of goods and it is possible that, with specialization and division of labor, economic processes might have given rise to selection pressures that fluctuate over time (Penke \& Jekola, 2016). In particular, exchange may be related to personality if it reflects differences in patterns of comparative advantage (e.g. Heckman, Strixrud, \& Urzua, 2006). Comparative advantage is a notoriously misunderstood concept so its logic is depicted in Figure 4 (for a more detailed account, see Ridley, 2010; Sowell, 2015). Comparative advantage refers to how the individual is not equally efficient at all the things he or she can produce, and so there will be one type of thing they will be better at doing relative to the other options they have available. As long as all parties are not equally good at producing all possible things, it is rational for them to exchange.

People seem to instinctively notice what they are uniquely good at and find doing what they are good at reinforcing. In this way, people become specialized in particular "niches" within their social groups (Scarr \& McCartney, 1983). Yet humans seem to have strong predispositions that militate against exchange, such as a tendency to misinterpret win-win opportunities for zero-sum situations (Pinker, 1997; Sowell, 2011). If people really do sort themselves into roles based on their innate differences, as suggested by Roy (1951), then the more similar people are the less obvious their unique comparative advantages might be. It is plausible that comparative advantages will be more likely to be detected the more noticeably individuals vary, and so there will be a more powerful the incentive to trade. Tendencies countering exchange might therefore be more likely to be overturned, and specializations cultivated, if genetic diversity makes individual differences in innate talents more salient. 
(a)

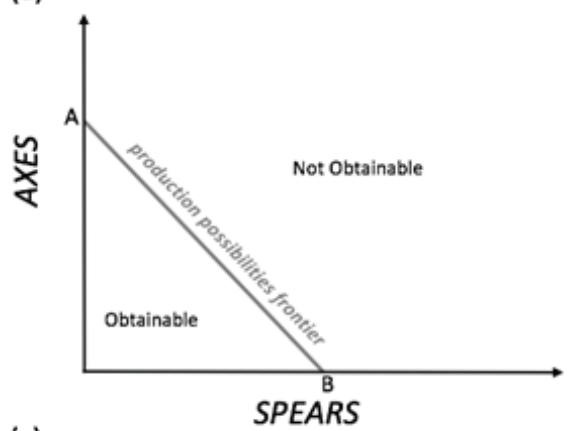

(c)

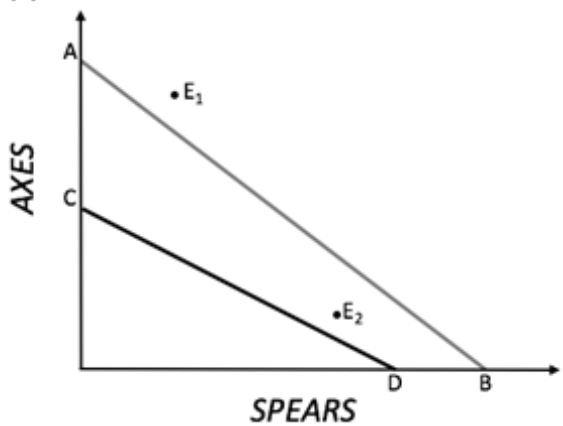

(b)

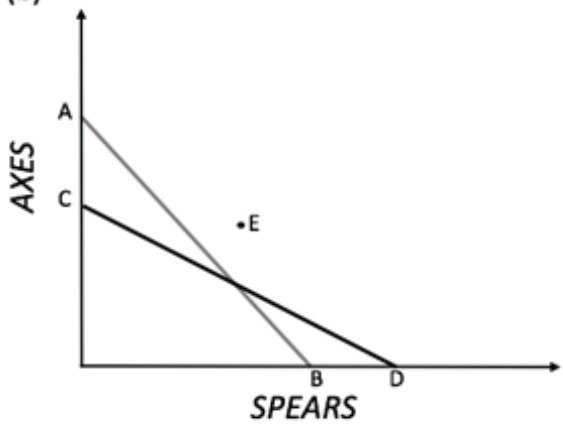

(d)

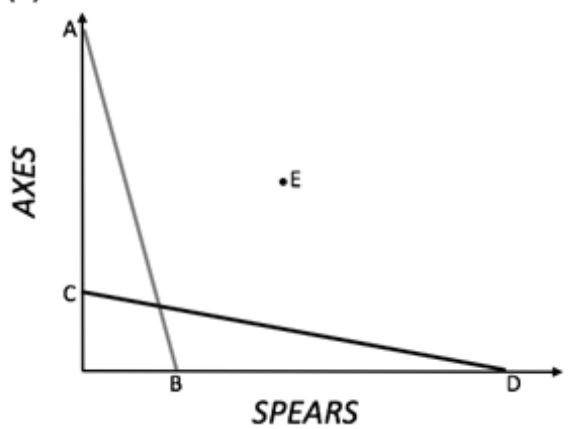

Figure 4. Production Possibilities and trade for spears and axes. (a) Line AB represents the frontier of all combinations of spears and axes that could be produced if an individual's resources are efficiently used. To the right of this line are things that are not obtainable. (b) Line AB and $\mathrm{CD}$ show production possibility frontiers for two individuals who have a comparative advantage in producing axes and spears respectively. Specialization and exchange allows combinations to be reached that exceed the production possibilities of each individual (e.g. point E). It is still rational to specialize and trade even when $\mathrm{AB}$ has an absolute advantage over $\mathrm{CD}$ (c), with both being able to achieve gains from trade (e.g., $E_{1}$ for individual $A B$ and $E_{2}$ for individual $C D$ ). (d) Further, as each individual specializes, their extra productivity in one task grows enormously due to acquiring task-specific skills/knowledge and no longer having to perform the other (Becker \& Murphy, 1992).

Natural Selection can be involved to the extent that genetic variance contributes to these differences, and thus we have an alternative explanation for personality insofar as the relevant differences are psychological. If there are fitness benefits to individuals who have comparative advantages and act on them, selection may thereby favor the maintenance of genetic variance underpinning these differences, perhaps even if the particular tasks people specialize in varies from generation to generation.

Archeological evidence suggests that exchange did not grow slowly over the course of human history but emerged rather suddenly (Ridley, 2010). 
Therefore, a prediction is that diversity in personality genes should be relatively recent in origin and increase within populations and places at times when trade is most evident. In particular, the greatest increases in specialization and division of labor have occurred in the last few centuries and in industrialized economies, which is where the greatest increase in personality genes should be observed. This contrasts with what we would expect from the Red Queen model, which holds that personality genes should be ancient in origin and as old as culture itself.

Another prediction could be tested experimentally. In laboratory simulations, it seems a robust finding that systems specialization and exchange spontaneously arise between participants, with people gradually discovering their own comparative advantage and trading things they produce (Crocket, Smith, \& Wilson, 2009). It follows from this economic model that using less or more psychologically diverse samples, as reflected by personality measures, should affect the ease with which such cooperation arises. By contrast, a Red Queen model says nothing obvious about whether exchange in such samples would be affected by personality.

\subsection{Other accounts}

Most other approaches to explaining the evolution of personality fall into the broad categories of (1) frequency dependence; and (2) mutation-balance. Frequency-dependent explanations suggest that genetic variation is maintained by some sort of selection that changes direction often enough to preserve genes in the population. The Red Queen model is an example of frequency-dependent selection, but others have been suggested (for examples see Figeuredo et al., 2005; Wilson, 1994). Mutation balance assumes that the rates of mutation for the relevant loci are sufficiently high that new variation in personality genes is constantly being created in a population, rather than the same variation being maintained.

Molecular evidence tends to favor frequency-dependent over mutationbalance as explaining personality (Penke, Denissen, \& Miller, 2007; Penke \& Jokela, 2016). The role of new mutations will therefore not be discussed again here until we turn to the discussion of intelligence. As regards previous frequency-dependent models of personality, some points are worth making here. Firstly, the theory we have outlined is not incompatible with many other plausible sources of fluctuating selection. In particular, Buss (2009) points out the variability that measures of personality reflect might represent differences in "strategies" for human genes in maximizing their fitness. Like the comparative advantage process adumbrated above, this does not exclude the notion of 
cultural parasites playing the role we envisage. Moreover, since these mostly social strategies are likely to involve interacting through culture, genetic variation in acquiring these alternative strategies and their varying costs might even be looked at in terms of immunity to parasitic memes.

For instance, Del Giudice (2012) proposes that changes in the sex ratio could favor variation in personality traits because the underlying genes affect responses to changes in the opportunities and costs of being male or female. But Red Queen dynamics are also thought to drive various cases of sexual selection (Hamilton, 2001; for reviews, see Beltran-Bech \& Richard, 2014; Ridley, 1993), with particular features arising because they are relevant to immunity, such as the degree of red coloration in the eyes of birds indicating resistance to blood parasites. Changes in the sex ratio of bird populations would not mean that red coloration ceased to be a factor in mate choice driven by host-parasite interactions, although it may change the relative importance of redness to the decisions of either sex. It is not inconceivable that sexual selection has also resulted in people choosing mates based on signals that indicate resistance to cultural parasites. Thus, if Del Giudice is correct that changes in the number of men and women in populations over time affects how "choosy" people of either sex can be, then the Red Queen model favored here would not be ruled out by the truth of the sex ratio hypothesis. Indeed, it may complement the sex-ratio approach by suggesting why certain features affect the nature of this mate choice and why.

Secondly, although a Red Queen process is not necessarily incompatible with other frequency-dependent explanations, it does make different molecular predictions. Specifically, most frequency-dependent models predict that the genes which cycle should be concentrated at relatively few loci, and that these genes should be maintained at moderate frequencies (for further discussion see Del Guidice, 2012). More specifically, other antagonistic coevolution frequency-dependent models would predict relatively few genes should explain most of the variation in the relevant behavioral traits and they should be close together in the genome (Rice \& Holland, 1997). As mentioned, Red Queen theory, by contrast, expects numerous genes of infinitesimal effect scattered throughout the genome. Moreover, when many types of parasites are involved, the relevant host genes may show quite varying time periods for their cycling with many being rare and only subtly changing in frequency or even showing quite chaotic patterns (Shenk, Traulsen, \& Gonkhale, 2017). Existing evidence seems to argue against the prediction of few genes of large effects concentrated in the genome and therefore against simple frequency-dependent models (Del Guidice, 2012). While it is too early to rule out other frequency-dependent models, since the current state of knowledge might be more reflective of 
methodological limitations than any empirical reality, it should be noted that these findings seem more in line with our Red Queen interpretation.

\section{DISCUSSION}

Red Queen theory was originally developed by population genetic models and genetic algorithm simulations, and is the focus of much ongoing research in the biological sciences. It is a small step to extend it from genes affecting physiological and anatomical features to include genes affecting the mind. We have shown how such a step specifies a mechanism which can explain personality and otherwise unconnected observations while speaking to further empirical tests. Red Queen dynamics are often thought to operate in numerous systems where what act as "parasites" in the relevant sense are replicators we would seldom otherwise consider parasites in the same way that we might regard such pathogens as protozoa or bacteria, with social interactions being a likely source of much of such "parasitism" in humans (Rice \& Holland, 1997). If there is no need for a sharp dividing line between biological and cultural parasites in terms of their evolutionary effects, then the same basic understanding of host-parasite evolutionary dynamics may therefore be applied to understanding gene-culture coevolution.

The alert reader will also notice that the assumptions we have made about cultural change are minimal. Despite its immense importance, "culture" is conceptually tricky to quantify and accurately measure, and so seldom enters empirical analyses. We see it as a strength, rather than a weakness, of our model in that we can assign a fundamental role to culture in a testable model while being quite neutral as to what precise aspects of culture are parasitic and what are not. It might seem our application of the Red Queen theory presumes cyclical patterns in parasitic culture, and cyclical characteristics of culture have long been suspected (for examples, see Chapin, 1925; Sorokin, 1927; Eysenck, $1995)^{6}$. But there is no need to assume even this. Since memetic parasites probably evolve at least as rapidly as biological parasites, a simplifying assumption can be made which renders the need for detailed consideration of parasite population dynamics redundant. Namely, the parasite population can be treated as an abstract "regime of alternating fitness differences among the various host genotypes" without having to manifest measurable cycling patterns (Hamilton, 2001, p. 434).

Moreover, while there have been sophisticated philosophical discussions about the structure of memes and how best to conceive of them (e.g. Dennett, 2017; Velikovsky, 2017), our basic model is neutral regarding these details and so immune to previous criticisms of the meme concept (Roy, 2017a). We need 
only assume that (1) the replication of some units of culture is achieved through reducing the Darwinian fitness of their hosts without always producing offsetting fitness benefits to other human genes; (2) the rate at which these cultural items can adjust to exploit host defenses is faster than the rate at which host defenses can evolve; and (3) that genetically-determined differences in psychology affect how vulnerable people are to such cultural elements. These assumptions allow us to postulate culture as a selective aspect of people's environment that changes in response to human gene patterns, and this is the critical ingredient for Red Queen dynamics (Hamilton, 2001, p. 57).

On this view, a wider range of potential parasite-host interactions can be considered through its links with ontogenetic models of personality. An advantage is that this brings into consideration broader sources of evidence, such as whether changes in personality genes affect culture and vice versa. For example, allele frequencies can be shown to predict between-population variability in some cultural features (Chiao \& Blizinsky, 2010; Luo \& Han, 2014), while some non-random changes in gene frequencies reflect differences in personality characteristics between populations as well as trends within populations (Ciani \& Capiluppi, 2011). More generally, research converging from a range of sources indicates cultural and genetic change are reciprocally related (Kim \& Sasaki, 2014; Laland, Odling-Smee, \& Myles, 2010), and these may be interpreted in the framework of the present model.

In addition to the predictions made by this versus competing approaches, the present interpretation is unique in another respect. Whereas previous approaches focus on the implications of personality for the characteristics of the individual, the present paper considers the systemic implications of personality existing for cultural and evolutionary processes more broadly. It is suggested that personality is not only caused by cultural factors, but that its presence tends to constrain how harmful culture can become. If correct, the adage "You can fool all the people some of the time and some of the people all of the time, but you cannot fool all of the people all of the time" is valid partly because the genetic foundations of personality mean everyone is differently resistant to any particular scam.

It stands to reason that the harder it is to "fool all of the people all of the time" then the less duping there is likely to be overall. Speculating further, we show below how these dynamics might facilitate cognitive improvements over time, such as through better enabling the elimination of counterproductive ideas and so perhaps better enabling the discovery and spread of beneficial innovations. 


\subsection{Relevance to intelligence}

As a host's biological organization evolves increasing levels of sophistication, this increases opportunities for both parasitic and symbiotic cells to replicate by subterfuge of these wider varieties of tissues and physiological functions. The relationships in Darwinian fitness are depicted in Figure 5a, with pluses and minuses indicating increases and decreases in fitness respectively. The combination of evolutionary advantages enjoyed by parasites means they can exert negative feedback on evolutionary tendencies of the host to increase in complexity, thus offsetting benefits from more complex hosts being able to increasingly integrate non-parasitic, symbiotic replicators into their bodies and behavior. For example, as a host evolves layers of fur to help regulate body temperature, this creates new ecological niches for lice and fleas to exploit. In short, a blue whale has far more "ecological space" for communities of parasites to exploit, with its great mass and cell types, than more simply organized animals such as sponges.
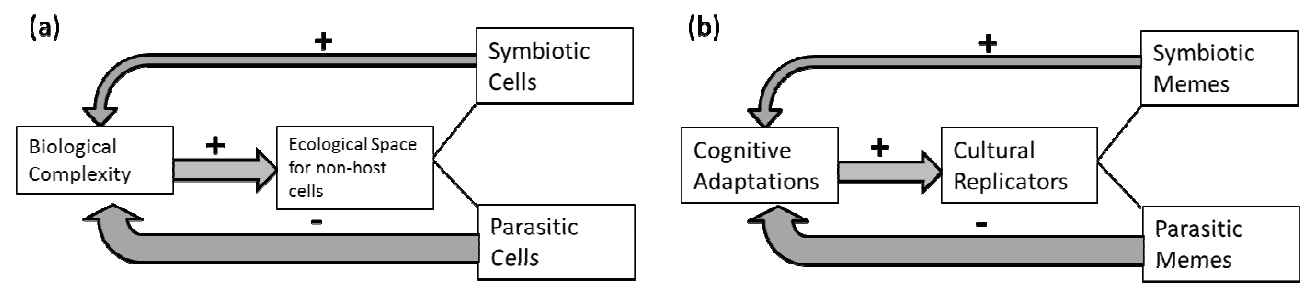

Figure 5. Influence of parasites on host-fitness and the evolution of increasing host-complexity. As a host species' biological organization becomes more complex then it creates more potential niches for parasites, in the same way more complexly organized rainforest or barrier reef encourages more species to flourish and diversify. (a) As more hosts tend to be loaded with parasites, this exerts a selection pressure against biological complexity. (b) By analogue, parasitic culture will exert a selective pressure against enculturation and, presumably, cognitive complexity.

The parallel to our view of cultural parasites and symbionts is illustrated in Figure $5 b$, where increasing levels of cognitive complexity (i.e. the evolution of the human intellect) increase opportunities for parasitic ideas to exert similar negative feedback. With a greater capacity for imagination and deception, there is also likely a greater capacity for the human brain to become detached from reality (Trivers, 2000). As the number of mental modules increases, so too does the number of psychological pathways that parasitic memes can evolve to exploit. Moreover, with more sophisticated social organization the opportunities for deceptive information to propagate between individuals and groups also 
rises. These tendencies can severely counteract the benefits people get from acquiring more knowledge and skills (e.g. Becker \& Murphy, 1992).

Obviously, the hosts may evolve adaptations that bias them towards acquiring symbiotic or useful culture and eliminate parasitic elements. But as we have seen, no single immune response can last for long before becoming over-run with parasites. As it becomes successful it will present a target to which rapidly evolving parasites will be selected to adapt. The Red Queen process can constantly alter such a "target," however, by continuously producing unique genotypes and therefore subtle psychobiological variation to disrupt the evolution of parasitic memes. It is easy to see that if the virulence of the parasites is constrained in this way, the host species might be freer to evolve increased intelligence (Figure 6).

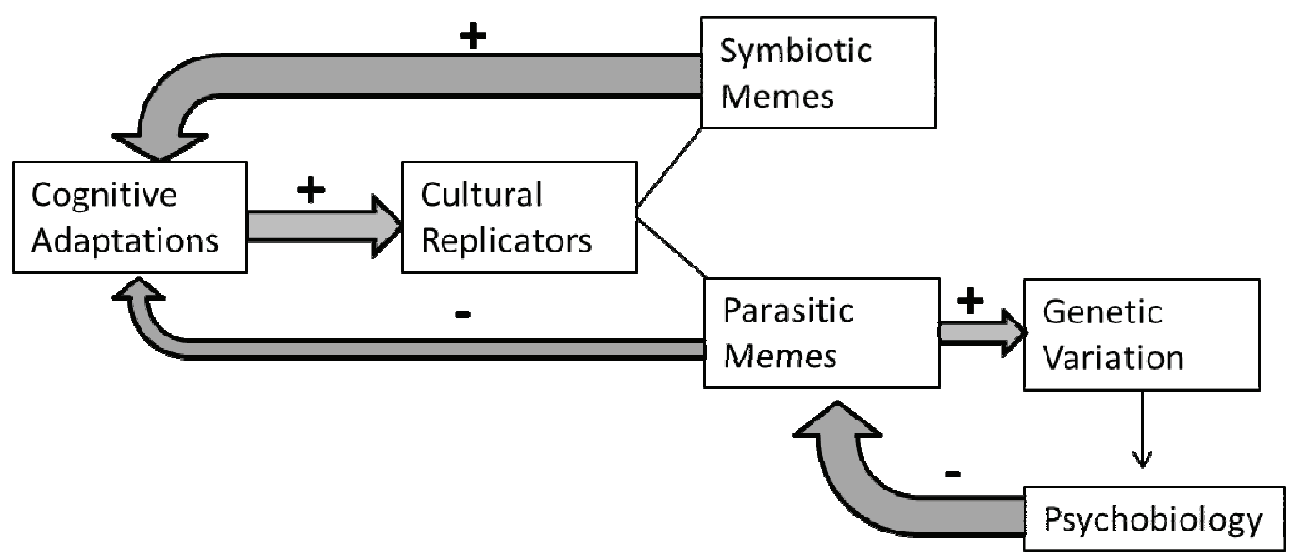

Figure 6. Model of a Red Queen process attenuating cultural parasitic virulence. A selection pressure from parasites favors genetic diversity of a certain kind controlling psychobiological characteristics. Such diversity, in turn, decreases the capacity of parasitic memes to decrease the fitness of cognitive adaptations for cultural acquisition.

Put roughly, genetic variation (personality genes) could limit how deleterious and how common bad ideas could become. By preventing cognitive adaptations from becoming overrun with parasites, this might in turn make it easier to eliminate fitness-reducing memes from culture altogether. If correct, the origins of personality alleles should coincide with the emergence of genetic changes that have promoted human intelligence. 


\subsection{Heritability across the lifespan}

Immunological diversity should be associated with physiological health because of the resistance to parasites it provides. Similarly, psychological diversity should be associated with greater "mental fitness". Whatever the specific cognitive abilities that have been selected for in human ancestors, it is plausible that these are partly correlated with measures of cognitive ability such as IQ ${ }^{7}$. If so, and "mental fitness" is impaired by parasites, then measures of cognitive ability should show similar levels of heritability to personality. Briefly, people grow more intelligent as they acquire more skills and knowledge from culture. Individuals differ in their receptivity to memes that make them smarter and resistance to memes that make them dumber, and these differences determine how well people perform in these tests. If these differences in receptivity are affected by genetic variation, as argued above, then the such cumulative, compounding effects of genes should be reflected in scores on cognitive ability tests. Consistent with this reasoning are observations that IQ indeed shows low to moderate heritability when young that increases to very high levels $\left(h^{2}=.75\right)$ in late adulthood (Neisser et al., 1996).

\subsection{Mutation rates}

Under normal conditions, Natural Selection favors a zero-mutation rate. However, Hamilton (2001, p. 619) suggests that, when a Red Queen process is acting to create diversity in some aspects of immunity, it can allow a higher mutation rate in parts of the genome underpinning general immunological adaptations. These higher levels of mutation can occur when individuals choose their reproductive partners based on signals which indicate health. Combined with the Red Queen process acting to constantly shuffle immunity-related genes around over generations, the consequence of this 'sosiogenic' mate-choice is that genes which lead consistently to poor health outcomes become concentrated in just a few, unlucky individuals ${ }^{8}$. When those few are unable to successfully leave offspring, their combinations of the most deleterious genes are thereby eliminated.

In other words, genes that are sometimes good and sometimes not so good are kept in the gene pool by the Red Queen, but genes consistently associated with low fitness are eliminated when there is also mate choice based on selecting healthy partners. Thus, because the Red Queen process leads to more efficient elimination of the unfailingly bad mutations, Natural Selection permits a higher level of mutation in the relevant genes. 
In summary, a greater net number of advantageous mutations can arise which, in contrast to the bad genes, can then be ratcheted up to fixation in the gene-pool by selection (Hamilton, 2000, p.13). By offsetting the downside of higher mutation rates affecting psychological abilities, this allows more rapid adaptation, since the rate of increase in adaptation in a population is proportional to the amount of genetic variance for that feature (Fisher, 1930).

If the Red Queen process acts on genes affecting psychological variables, this is likely to have allowed an increase in mutation rates affecting the human brain, thus facilitating progressively more complex cognition to evolve. A prediction of the current model is that, compared to other phenotypes, there should be higher mutation rates in genes affecting individual differences in psychology in general, and high mutation rates associated with IQ in particular.

Some evidence can already be seen to be suggestive on this point. For example, the protocadherin gene family provides a molecular code which enables highly detailed neuronal wiring to be encoded genetically ( $\mathrm{Wu} \&$ Maniatis, 1999). Such a capacity for fine-scaled neural circuitry to be specified by the genome means it is likely that genes of this type have been favored by natural selection in humans, given that variations across other taxonomic groups are also thought to underpin species-specific adaptations (Noonan et al., 2004; Uddin et al., 2007; Wu, 2005). In line with Red Queen predictions, just as regions of the human genome that are mutation "hotspots" (where most mutations occur) are disproportionately genes involved in immune function, the protocadherin gene families in particular have especially high mutation rates (Chuang \& $\mathrm{Li}, 2004$ ). It is plausible that these and other genes might therefore be playing a role in the nervous system analogous to immune functions in other tissues, and so subject to the similar evolutionary dynamics.

\subsection{Homozygous fitness}

Finally, a Red Queen view of personality and intelligence provides an alternative interpretation of the Flynn effect. The Flynn effect refers to the broad increases in average IQ scores since IQ testing began and through the $20^{\text {th }}$ century (Flynn, 2007). The Flynn effect might have been a result of a Red Queen process, with rising intelligence produced by greater levels of genetic variance from increased migration and inter-breeding between human populations in recent centuries.

With sudden increases in the level of unique gene combinations for psychophysiological variables, subsequent generations will be especially able to escape the memetic parasites that have evolved to specialize in their ancestral populations. If such sudden and extreme increases in genetic diversity cause 
many memetic parasites to fall below critical frequencies and be lost, then the average level of intelligence in the population would presumably rise. It may be conceived that, with people escaping these parasites, this process might interact with the various sorts of feedback loops envisaged by Dickens and Flynn (2001) such that there would be a diffusion of intelligence-boosting, symbiotic memes displacing the parasites throughout the host population. Although conjectural, the key thing to note is that an upsurge in intelligence is predicted here whenever there is a large rise in the host population's genetic diversity.

It has been proposed elsewhere that increased movements and interbreeding of populations might have resulted in an increase in IQ by heterosis (Mingroni, 2007). Heterosis refers to situations when heterozygotes have a fitness advantage compared to homozygotes. It may be noted that the existing data Mingroni draws upon to support a heterosis explanation is equally consistent with the present thesis because both implicate genetic diversity as a cause of higher abilities.

The heterosis explanation and the present thesis make at least one diametrically opposite prediction, however, on which existing evidence cannot yet decide. This difference springs from the tendency of heterozygote genotypes at any particular locus to be more common than either of their respective homozygotes ${ }^{9}$. Heterozygotes are therefore exposed to parasites more often and so will be the genotypes parasites have most opportunity to adapt to (Hamilton, 2001). Thus, if individuals were genetically sequenced and given IQ tests, we would predict that those showing greater heterozygosity should tend to generally have lower IQ, if anything, than those homozygote for genes related to psychobiology.

\section{SUMMARY AND CONCLUSION}

Parasites evolve to specialize. Parasites therefore tend to do best when the defenses of their hosts are genetically uniform. If everyone was psychologically the same, memetic parasites could specialize in getting past whatever particular set of defenses each person has and steer human behavior towards spreading memes at the expense of genes. But sexual shuffling of genes into unique combinations can mean that adaptation by a parasite in response to the psychobiological subtleties of any particular host will be of only temporary benefit. Indeed, the more a parasite becomes specialized to any particular mentality the less optimal it will be at exploiting another mind. With sex constantly hindering the evolution of virulent parasites by producing ever varying psychologies to adjust to, maladaptive memes will be more likely to be lost from the population's culture. A statistical bias for loss of virulent parasites 
from the culture might then be expected and a higher mutation rate in genes for cognitive adaptation can occur.

Because the relevant genes that these Red Queen dynamics would be acting to preserve in the population support psychobiological variety, this gene-culture coevolution could explain why human personality evolved. This view provides a reinterpretation of many otherwise unconnected facts, while making predictions that can be tested against alternatives. It is not yet clear whether one or more of these other mechanisms might actually be interacting with Red Queen dynamics to drive the evolution of personality. For instance, intragenomic conflict might be an important source of new genetic variants, which then are used in a Red Queen process to provide resistance against parasites, which in turn increase the salience of complementary advantages between cooperating individuals. However, it is clear there are sufficiently diverging predictions across models that empirical tests can help determine the relative importance of a Red Queen process. As the efficiency of molecular techniques continues to radically improve, empirical tests of these models will become increasingly viable. In this way, the Red Queen may be extended to further explain why we are all individually so unique.

\section{Notes}

1 The "immune system" can be defined broadly across various levels of biological organization: influencing physical barriers such as skin; the structure of macromolecules; the use or disuse of chemicals that can be used by parasites as signals for guiding entry or the detection of hosts; variations in the active defenses of chemicals or cells, the production of so-called "password" molecules on cell-surfaces; and so forth (Hamilton, 2001; White \& Fenner, 1994).

${ }^{2}$ The point here is not to argue for the validity of any particular theory of personality development, nor is to argue that precise analogies exist between psychobiological pathways and immune responses. Rather, the point is to show existing ontogenetic theories fit easily with the general notion of their corresponding genetic variance acting to counteract the parasitic aspects of memes.

${ }^{3}$ For instance, consider experiments by Solomon, Turner and Lessac (1968) where hungry dogs were presented with both horse meat and punishment. When tested after training, dogs punished whenever they approached the meat were better able to resist eating the meat and, if they eventually did, showed no signs of distress. Dogs that were punished only after they had started consuming the meat during training were later less able to resist approaching the 'taboo' food when tested even though they showed visible signs of intense emotional distress ("guilt reactions") once the food was eaten.

${ }^{4}$ This can be tested against heritability studies of diseases and personality. Heritability studies parse the environmental contributions into variation in phenotypes from the family environment in which the individual organism is raised (termed the shared environment) versus variation in phenotypes due to all other aspects environments that the organism encounters (the non-shared environment), and the contribution of genetic variance $\left(h^{2}\right)$.

5 Although there appears to be larger shared-environment contributions for political attitudes, this effect vanishes in significance when the likely effects of non-additive mating are controlled for (Eaves, Eysenck, \& Martin, 1989; Kandler, Bleidorn, \& Riemann, 2011) 
${ }^{6}$ For instance, there is much non-progressive cycling in financial markets, which can be interpreted epidemiologically as the spreading and declining of different parasitic memes (Lynch, 2000).

7 Two lines of evidence support this presumption: (1) all psychometric tests of cognitive ability with demonstrated validity show positive manifold (Neisser et al., 1996) (so even though our cognitive adaptations may well be very different constructs as those conceived of by g-theorists, it is reasonable to suppose that they would be positively correlated with scores on these tests); and (2) after controlling for body mass, brain size correlates with IQ (Rushton \& Jensen, 2005).

8 A corollary of this reasoning is that human mate choice should be determined by stimuli which indicate "mental fitness." The more powerful such mate-choice is, the more effective a Red Queen process will be in eliminating the relevant mutations and promoting cognitive adaptation. As already mentioned, Red Queen processes are powerful drivers of sosiogenic mate-choice.

${ }^{9}$ For instance, assuming both equal probability of homozygotes for alleles $P$ and $q$, there will tend to be a higher number of individuals with $P q$ at Hardy-Weinberg equilibrium than either with $P P$ or $q q$.

\section{Acknowledgments}

Thank you to our friend, Jody Cameron, for her proof-reading and helpful comments on an earlier draft of the paper.

\section{REFERENCES}

Auld, S. K., Wilson, P. J., \& Little, T. J. (2014). Rapid change in parasite infection traits over the course of an epidemic in a wild host-parasite population. Oikus, 123, 232-238.

Ball, J. A. (1984). Memes as replicators. Ethology and Sociobiology, 5, 145-161.

Barkow, J. H. (1989). The elastic between genes and culture. Ethology and Sociobiology, 10, $111-129$.

Balleine, B. W., Delgado, M. R., \& Hikosaka, O. (2007). The role of the dorsal striatum in reward and decision-making. The Journal of Neuroscience, 27, 8161-8165.

Balleine, B. W., \& O'Doherty, J. (2010). Human and rodent homologies in action control: Corticostriatal determinants of goal-directed and habitual action. Neuropsychopharmacology Reviews, 35, 48-69.

Barkley, R. A., Edwards, G., Laneri, M., Fletcher, K., \& Metivia, L. (2001). Executive functioning, temporal discounting, and sense of time in adolescents with attention deficit hyperactivity disorder (ADHD) and oppositional defiant disorder (ODD). Journal of Abnormal Child Psychology, 29, 541-556.

Becker, G. S., \& Murphy, K. M. (1992). The division of labor, coordination costs, and knowledge. The Quarterly Journal of Economics, 107, 1137-1160.

Beltran-Bech, S., \& Richard, F. J. (2014). Impact of infection on mate choice. Animal Behaviour, 90, 159-170.

Blackmore, S. (2010). Memetics does provide a useful way of understanding cultural evolution (pp. 255-270). In: F.J. Ayala \& R. Arp (Eds.), Contemporary debates in philosophy of biology. New York: Wiley Blackwell. 
Bradfield, L. A., \& Balleine B. W. (2016). The learning and motivational processes controlling goal-directed action and their neural bases. In: Decision neuroscience: An integrative perspective, pp. 71-80, http://dx.doi.org/10.1016/B978-0-12-805308-9.00006-3

Brown, W. M. (2001). Genomic imprinting and the cognitive architecture mediating human culture. Journal of Cognition and Culture, 1, 251-258.

Burger, J., \& Gochfeld, M. (2003). Parrot behavior at Rio Manu (Peru) clay lick: Temporal patterns, associations, and antipredator responses. Acta Ethologica, 6, 23-34.

Buss, D. M. (2009). How can evolutionary psychology successfully explain personality and individual differences? Psychological Science, 4, 359-366.

Chabris, C. F., Lee, J. J., Cesarini, D., Bengamin, D. J., \& Laibson, D. I. (2015). The fourth law of behavior genetics. Current Directions in Psychological Science, 24, 304-312.

Chapin, S. F. (1925). A theory of synchronous culture cycles. Journal of Social Forces, 3, 596604.

Chuang, J. H., \& Li, H. (2004). Functional bias and spatial organization of genes in mutation hot and cold regions of the human genome. PLOS Biology, 2, 253-263.

Chiao, J. Y., \& Blizinsky, K. D. (2010). Culture-gene coevolution of individualism - collectivism and the serotonin transporter gene. Proceedings of the Royal Society of London B, 277, 529537.

Ciani, A. C., \& Capiluppi, C. (2011). Gene flow by selective emigration as a possible cause for personality differences between small islands and mainland populations. European Journal of Personality, 25, 53-64.

Ciani, A. S., Capiluppi, C., Veronese, A., \& Guiseppe, S. (2006). The adaptive value of personality differences revealed by small island population dynamics. European Journal of Personality, 21, 3-22.

Cooke, G. S., \& Hill, A. V. S. (2001). Genetics of susceptibility to human infectious disease. Nature Reviews Genetics, 2, 967-977.

Corr, P. J. (2004). Reinforcement sensitivity theory and personality. Neuroscience and Biobehavioral Reviews, 28, 317-332.

Corr, P. J., \& McNaughton, N. (2012). Neuroscience and approach/avoidance personality traits: A two stage (valuation-motivation) approach. Neuroscience and Biobehavioral Reviews, 36, 2339-2354.

Corr, P. J., \& Mutinelli, S. (2017). Motivation and young people's career planning: A perspective from the reinforcement sensitivity theory of personality. Personality and Individual Differences, 106, 126-129.

Crespi, B., Summers, K., \& Dorus, S. (2011). Adaptive evolution of genes underlying schizophrenia. Proceedings of the Royal Society of London B, 274, 2801-2810.

Crocket, S., Smith, V. L., \& Wilson, B. J. (2009). Exchange and specialisation as a discovery process. The Economic Journal, 119, 1162-1188.

Dawkins, R. (1976). The selfish gene. Oxford: Oxford University Press.

Dawkins, R. (1982). The extended phenotype. Oxford: W. H. Freeman.

Dawkins, R. (1990). Parasites, desiderata lists and the paradox of the organism. Parasitology, $100,63-73$.

Del Giudice, M. (2012). Sex ratio dynamics and fluctuating selection on personality. Journal of Theoretical Biology, 297, 48-60.

Dennett, D. C. (1995). Darwin's dangerous idea. New York: Viking Penguin.

Dennett, D. C. (2006). Breaking the spell: Religion as a natural phenomenon. New York: Viking Penguin.

Dennett, D. C. (2017). From bacteria to Bach and back: The evolution of minds. W. W. Norton.

De Wit, H. (2009). Impulsivity as a determinant and consequence of drug use: A review of underlying processes. Addiction Biology, 14, 22-31. 
Dickens, W. T., \& Flynn, J. R. (2001). Heritability estimates versus large environmental effects: The IQ paradox resolved. Psychological Review, 108, 346-369.

Eaves, L. J., Eysenck, H. J., \& Martin, N. G. (1989). Genes, culture and personality: An empirical approach. London: Academic Press.

Eaves, L. J., Heath, A., Martin, N., Maes, N. H., Neale, M., Kendler, K., \& Corey, L. (1999). Comparing the biological and cultural inheritance of personality and social attitudes in the Virginia 30,000 study of twins and their relatives. Twin Research, 2, 62-80.

Ebert, D., \& Hamilton, W. D. (1996). Sex against virulence: The coevolution of parasitic diseases. Trends in Ecology \& Evolution, 11, 79-82.

Eysenck, H. J. (1967). The biological basis of personality. Springfield, II Charles, C. Thomas.

Eysenck, H. J. (1977). Crime and personality ( $3^{\text {rd }}$ ed.). London: Routledge \& Kagen Paul.

Eysenck, H. J. (1992). Four ways five factors are not basic. Personality and Individual Differences, 13, 667-673.

Eysenck, H. J. (1993). Creativity and personality: Suggestions for a theory. Psychological Inquiry, 4, 147-178.

Eysenck, H. J. (1995). Genius: The natural history of creativity. Cambridge: Cambridge University Press.

Eysenck, H. J. (1997). Personality and experimental psychology: The unification of psychology and the possibility of a paradigm. Journal of Personality and Social Psychology, 73, 12241237.

Figueredo, A. J., Va'squez, G., Brumbach, B. H., Sefcek, J. A., Kirsner, B. R., \& Jacobs, W. J. (2005). The $K$-factor: Individual differences in life history strategy. Personality and Individual Differences, 39, 1349-1360.

Fisher, R. A. (1930). The genetical theory of natural selection: A complete variorum edition. Oxford University Press.

Fleger, J., Kodym, P., \& Tolarová, V. (2000). Correlation of duration of latent Toxoplasma gondii infection with personality changes in women. Biological Psychology, 53, 57-68.

Flynn, J. R. (2007). What is intelligence? New York: Cambridge University Press.

Frost, R., \& McNaughton, N. (2017). The neural basis of delay discounting: A review and preliminary model. Neuroscience and Biobehavioral Reviews.

Funk, C. L., Smith, K. B., Alford, J. R., Hibbing, M. V., Eaton, N. R., Krueger, R. F., Eaves, L. J. \& Hibbing, J. R. (2012). Genetic and environmental transmission of political orientations. Political Psychology. doi: 10.1111/j.1467-9221.2012.00915.x

Gray, J. A., \& McNaughton, N. (2000). The neuropsychology of anxiety ( $2^{\text {nd }}$ ed). Oxford: Oxford University Press.

Gregg, C., Zhang J., Weissbourd, B., Luo, S., Schrothh, G. P., Haig, D., \& Dulac, C. (2011). High resolution analysis of parent-of-origin allelic expression in the mouse brain. Science, 329, 643-648.

Haig, D. (1997). Parental antagonism, related asymmetries, and genomic imprinting. Proceedings of the Royal Society of Londo B, 264, 1657-1662.

Haig, D. (2001). Genomic imprinting and kinship. New Brunswick: Rutgers University Press.

Haig, D. (2004). Genomic imprinting and kinship: how good is the evidence? Annual Review of Genetics, 38, 553-585.

Hamilton, W. D. (1980). Sex versus non-sex versus parasite. Oikos, 35, 282-290.

Hamilton, W. D. (1982). Pathogens as causes of genetic diversity in their host populations. In M. Anderson \& R. May (Eds.), Population biology of infectious disease (pp. 269-296). Berlin: Springer-Verlag.

Hamilton, W. D. (1987). Kinship, recognition, disease, and intelligence. In Y. Ito, J. K. Brown, \& Kikkawa, J. (Eds.), Animal societies: Theories and facts. Tokyo: Japan Scientific Societies Press. Reprinted in Hamilton, W. D. (2001). Narrow roads to gene land: The collected 
papers of W.D. Hamilton Volume 1: Evolution of social behaviour. Oxford: Oxford University Press.

Hamilton, W. D. (1996). Sex against virulence: the coevolution of parasitic diseases. Trends in Ecology and Evolution, 11, 79-82.

Hamilton, W. D. (2001). Narrow roads of gene land: The Collected papers of W.D. Hamilton Volume 2: Evolution of sex. Oxford: Oxford University Press.

Hamilton, W. D., \& Zuk, M. (1982). Heritable fitness and bright birds: a role for parasites? Science, 218, 384-387.

Hamilton, W. D., Axelrod, R., \& Tanese, R. (1990). Sexual reproduction as an adaptation to resist parasites (a review). PNAS, 87, 3566-3573.

Heckman, J. J., Stixrud, J., \& Urzua, S. (2006). The effects of cognitive and noncognitive abilities on labor market outcomes and social behavior. Journal of Labor Economics, 24, 411-482.

Höhler, T., Reuss, E., Evers, N., Dietrich, E., Tirrner, C., Freitag, C. M., Vollmar, J., Schneider, P. M., \& Fimmers, R. (2002). Differential genetic determination of immune responsiveness to hepatitis B surface antigen and to hepatitis A virus: a vaccination study in twins. The Lancet, 360, 991-995.

Jaenike, J. (1978). A hypothesis to account for the maintenance of sex within populations. Evolutionary Theory, 3, 191-194.

Jokela, M. (2012). Birth-cohort effects in the association between personality and fertility. Psycholical Science, 23, 835-841.

Kandler, C., Bleidorn, W., \& Riemann, R. (2011). Left or right? Sources of political orientation: The roles of genetic factors, cultural transmission, assortative mating, and personality. Journal of Personality and Social Psychology, 102, 633-645.

Kim, H. S., \& Sasaki, J. Y. (2014). Cultural neuroscience: Biology of the mind in cultural contexts. Annual Review of Psychology, 65, 487-514.

Kimman, T. G. (2001). Genetics of infectious disease susceptibility. Dordrecth: Kluwer Academic Publishers.

Laland, K. N., Odling-Smee, J., \& Myles, S. (2010). How culture shaped the human genome: Bringing genetics and the human sciences together. Nature Reviews Genetics, 11, 137-148.

Lee, C. A., Derefinko, K. J., Milich, R., Lynam, D. R., \& DeWall, N. (2017). Longitudinal and reciprocal relations between delay discounting and crime. Personality and Individual Differences, 111, 193-198.

Luo, S., \& Han, S. (2014). The association between an oxytocin receptor gene polymorphism and cultural orientations. Culture and Brain, 2, 89-107.

Lynch, A. (2000). Thought contagions in the stock market. The Journal of Psychology and Financial Markets, 1, 10-23.

McNaughton, N., \& Corr, P. J. (2004). A two-dimensional neuropsychology of defense: Fear/anxiety and defensive distance. Neuroscience and Biobehavioral Reviews, 28, 285305.

McNaughton, N., \& Wickens, J. (2004). Hebb, pandemonium and catastrophic hypermesia: The hippocampus as a suppressor of inappropriate associations. Cortex, 39, 1139-1163.

Mingroni, M. A. (2007). Resolving the IQ paradox: Heterosis as a cause of the Flynn effect and other trends. Psychological Review, 114, 806-829.

Mokkonen, M., \& Crespi, B. J. (2015). Genomic conflicts and sexual antagonism in human health: Insights from oxytocin and testosterone. Evolutionary Applications, 8, 307-325.

Morran, L. T., Schmidt, O. G., Gelarden, I. A., Parrish, R. C., \& Lively, C. M. (2011). Running with the Red Queen: host-parasite coevolution selects for biparental sex. Science, 333, 216218. 
Neisser, U., Boodoo, G., Bouchard Jr, T. J., Boykin, A. W., Brody, N., Ceci, S. J., Halpern, D. F., Lochlin, J. C., Perloff, R., Sternberg, R. J., \& Urbina, S. (1996). Intelligence: Knowns and unknowns. American Psychologist, 51, 77-101.

Noonan, J. P., Grimwood, J., Schmutz, J., Dickson, M., \& Myers, R. M. (2004). Gene conversion and the evolution of protocadherin gene cluster diversity. Genome Research 14: 354-366.

Penke, L., Denissen, J. J. A., \& Miller, G. F. (2007). The evolutionary genetics of personality. European Journal of Personality, 21, 549-587.

Penke, L., \& Jokela, M. (2016). The evolutionary genetics of personality revisited. Current Opinion in Psychology, 7, 104-109.

Peters, A. D., \& Lively, C. M. (1999). The Red Queen and fluctuating epistasis: A population genetic analysis of antagonistic coevolution. The American Naturalist, 154, 393-405.

Pinker, S. (1997). How the mind works. New York: Norton.

Povey, S., Cotter, S. C., Simpson, S. J., \& Wilson, K. (2014). Dynamics of macronutrient and self-medication and illness-induced anorexia in virally infected insects. Journal of Animal Ecology, 83, 245-255.

Rabajante, J. F., Tubay, J. M., Ito, H., Uehara, T., Kakishima, S., Satoru, M., Yoshimura, J., Ebert, D. (2016). Host-parasite Red Queen dynamcis with phase-locked rare genotypes. Science Advances, 2, e1501548. doi: 10.1126/sciadv.1501548

Raubenheimer, D., \& Simpson, S. J. (2009). Nutritional PharmEcology: Doses, nutrients, toxins, and medicines. Integrative and Comparative Biology, 49, 329-337.

Rice, W. R., \& Holland, B. (1997). The enemies within: Intergenomic conflict, interlocus contest evolution (ICE), and the intraspecific Red Queen. Behavioral Ecolology and Sociobiology, 41, 1-10.

Richerson, P. J., \& Boyd, R. (2006). Not by genes alone: How culture transformed human evolution. Chicago: University of Chicago Press.

Ridley, M. (1993). The Red Queen: Sex and the evolution of human nature. London: Viking.

Ridley, M. (2010). The rational optimist: How prosperity evolves. New York: Harper.

Rovers, M., Haggard, M., Gannon, M., Koepen-Schomerus, G., \& Plomin, R. (2002). Heritability of symptom domains in Otitis Media: A longitudinal study of 1,375 twin pairs. American Journal of Epidemiology, 155, 958-964.

Roy, A. D. (1951). Some thoughts on the distribution of earnings. Oxford Economic Papers, 3, $135-156$.

Roy, D. J. (2017a). Myths about memes. Journal of Bioeconomics, 1-25. doi:10.1007/s10818$017-9250-2$

Roy, D. J. (2017b). A conditioning model of delusion. Neuroscience \& Biobehavioral Reviews, 80, 223-239. doi: 10.1016/j.neubiorev.2017.05.024

Rushton, J. P., \& Jensen, A. R. (2005). Thirty years of research on race differences in cognitive ability. Psychology, Public Policy, and Law, 11, 235-294.

Sackton, T. B., Lazzaro, B. P., Schlenke, T. A., Evans, J. D., Hultmark, D., \& Clark, A. G. (2007). Dynamic evolution of the innate immune system in Drosophila. Nature Genetics, 39, 1461-1468.

Sahneh, F. D., \& Scoglio, C. (2013). May the best meme win!: New exploration of competitive epidemic spreading over arbitrary multi-layer networks. arXiv preprint arXiv:1308.4880.

Scarr, S., \& McCartney, K. (1983). How people make their own environments: A theory of genotype $\rightarrow$ environment effects. Child Development, 54, 424-435.

Schenk, H., Traulsen, A., \& Gokhale, C. S. (2017). Chaotic provinces in the kingdom of the Red Queen. Journal of Theoretical Biology, 431, 1-10.

Schmidt-Hempel, P. (2008). Parasite immune evasion: A momentous molecular war. Trends in Ecology and Evolution, 23, 318-326. 
Schmidt-Hempel, P. (2011). Evolutionary parasatology. London: Oxford University Press. Viking.

Seger, J., \& Hamilton, W. D. (2001). Parasites and sex. In: W. D. Hamilton Narrow roads of gene land: The collected papers of W.D. Hamilton Volume 2: Evolution of sex (pp. 427-448). Oxford: Oxford University Press. (Originally published in Michod, R.E., \& Levin, B. R. (Eds.), The evolution of sex: An examination of current ideas. (1988). Sunderland: Sinauer Associates).

Sheperd, J., \& McKelvey, B. (2009). An empirical investigation of organizational memetic variation. Journal of Bioeconomics, 11, 135-164.

Simonton, D. K. (2010). Creative thought as blind-variation and selective-retention: Combinational models of exceptional creativity. Physics in Life Reviews, 7, 156-179.

Skinner, B. F. (1938). The behaviour of organisms. New York: Appleton-Century-Crofts.

Skinner, B. F. (1984). Selection by consequences. The Behavioural and Brain Sciences, 7, $477-$ 510 .

Smith, K. (2004). The evolution of vocabulary. Journal of Theoretical Biology, 228, 127-142.

Solomon, R. L., Turner, L. H., \& Lessac, M. S. (1968). Some effects of delay of punishment on resistance to temptation in dogs. Journal of Personality and Social Psychology, 8, 233-238.

Sorokin, P. A. (1927). A survey of the cyclical conceptions of social and historical processes. Social Forces, 6, 28-40.

Sowell, T. (1980). Knowledge \& decisions. New York: Basic Books.

Sowell, T. (2009). Applied economics: Thinking beyond stage one ( $2^{\text {nd }} E d$.). New York: Basic Books.

Sowell, T. (2011). Economic facts and fallacies. New York: Basic Books.

Sowell, T. (2015). Basic economics (5 ${ }^{\text {th }}$ Ed.). New York: Basic Books.

Stoeber, J., \& Corr, P. J. (2017). Perfectionism, personality, and future-directed thinking: Further insights from revised Reinforcement Sensitivity Theory. Personality and Individual Differences, 105, 78-83.

Trivers, R. L. (2000). The elements of a scientific theory of self-deception. Annals of the New York Academy of Sciences, 907, 114-131.

Trofimova, I., \& Robbins, T. W. (2016). Temperament and arousal systems: A new synthesis of differential psychology and functional neurochemistry. Neuroscience and Biobehavioral Reviews, 64, 382-402.

Tyler, T. (2011). Memetics: Memes and the science of cultural evolution. Scotts Valley: Createspace.

Uddin, M., Goodman, M., Erez, O., Romero, R., Liu, G., Islam, M., Opazo, J. C., Sherwood, C. C., Grossman, L. I., \& Wildman, D. E. (2007). Distinct genomic signatures of adaptation in pre- and postnatal environments during human evolution. PNAS, 9, 3215-3220.

Velikovsky, J. T. (2017). Chapter 405: The Holon/Parton Structure of the Meme, or, The unit of culture. In: M. Khosrow-Pour (Ed.), Encyclopedia of information science and technology, Fourth Edition (pp. 4666-4678). New York: IGI Global.

Voight, B. F., Kudaravalli, S., Wen, X., \& Pritchard, J. K. (2006). A map of recent positive selection in the human genome. PLoS Biology, 4, doi:10.1371/journal.pbio.0040072

Wang, E. T., Kodama, G., Baldi, P., \& Moyzis, R. K. (2005). Global landscape of recent inferred Darwinian selection for Homo Sapiens. PNAS, 103, 135-140.

White, D. O., \& Fenner, F. J. (1994). Medical Virology. Academic Press.

Williams, G. C. (1957). Pleitropy, Natural Selection, and the Evolution of Senescence. Evolution, $11,398-411$.

Williams, G. C. (1966). Adaptation and natural selection. Princeton: Princeton University Press. 
Williams-Blangero, S., McGarvery, S. T., Subedi, J., Rai, D. R., Jha, B., Olds, G. R., Guanling, W., \& Blangero, J. (2002). Genetic component to susceptibility to Trichuris trichiura: Evidence from two Asian populations. Genetic Epidemiology, 22, 254-264.

Williamson, S. H., Hubisz, M. J., Clark, A. G., Payseur, B. A., Bustamante, C. D., \& Nielsen, R. (2007). Localizing recent adaptive evolution in the human genome. PLOS Genetics, 3: e90. doi:10.1371/journal.pgen.0030090

Wilson, D. S. (1994). Adaptive genetic variation and human evolutionary psychology. Ethology and Sociobiology, 15, 219-235.

Wong, A. C. N., Holmes, A., Ponton, F., Lihoreau, M., Wilson, K., Raubenheimer, D., \& Simpson, S. J. (2015). Behavioral microbiomics: A multi-dimensional approach to microbial influences on behavior. Frontiers in Microbiology, 6, 1359. doi: 10.3389/fmicb.2015.01359

$\mathrm{Wu}$, Q. (2005). Comparative genomics and diversifying selection of clustered vertebrate protocadherin genes. Genetics, 169, 2179-2188.

Wu, W., \& Maniatis, T. (1999). A striking organization of a large family of human neural cadherin-like cell adhesion genes. Cell, 97, 779-790.

Zuckerman, M. (1991). Psychobiology of psychobiology of personality. Cambridge, UK: Cambridge University Press.

Zuckerman, M. (1994). Behavioral expressions and biosocial bases of sensation seeking. Cambridge: Cambridge University Press.

Zuckerman, M. (2005). Psychobiology of personality (second edition, revised and updated). New York: Cambridge University Press.

Zuckerman, M., \& Glicksohn, J. (2016). Hans Eysenck's personality model and the constructs of sensation seeking and impulsivity. Personality and Individual Differences, 103, 48-52. 